\title{
UV Aerosol Indices from SCIAMACHY: introducing the SCattering Index (SCI)
}

\author{
M. J. M. Penning de Vries, S. Beirle, and T. Wagner \\ Max Planck Institute for Chemistry, Mainz, Germany \\ Received: 27 April 2009 - Published in Atmos. Chem. Phys. Discuss.: 19 June 2009 \\ Revised: 7 December 2009 - Accepted: 9 December 2009 - Published: 21 December 2009
}

\begin{abstract}
The Absorbing Aerosol Index (AAI) is a useful tool for detecting aerosols that absorb UV radiation especially in cases where other aerosol retrievals fail, such as over bright surfaces (e.g. desert) and in the presence of clouds. The AAI does not, however, consider contributions from scattering (hardly absorbing) aerosols and clouds: they cause negative AAI values and are usually disregarded. In this paper, we demonstrate the use of the AAI's negative counterpart, the SCattering Index (SCI) to detect scattering aerosols. Consideration of the full UV Aerosol Index scale is of importance if the Aerosol Index is to be used for the quantification of aerosol absorption in the future.

Maps of seasonally averaged SCI show significantly enhanced values in summer in Southeast USA and Southeast Asia, pointing to a high production of scattering aerosols (presumably mainly sulphate aerosols and secondary organic aerosols) in this season. The application of a cloud filter makes the presence of scattering aerosols even more clear. Radiative transfer calculations were performed to investigate the sensitivity of AAI and SCI to cloud parameters, and it is demonstrated that clouds cause significant SCI, in some special cases even small AAI values. The results from cloud modelling imply that cloud effects need to be taken into account when AAI and SCI are used in a quantitative manner.

The paper concludes with a comparison of aerosol parameters from AERONET and our Aerosol Indices (AAI and SCI) from SCIAMACHY, where reasonable agreement was found for six AERONET stations in Southeast USA, Southeast Asia, and Africa. These findings corroborate the suitability of SCI as a tool to detect scattering aerosols.
\end{abstract}

Correspondence to:

M. J. M. Penning de Vries

(marloes.penningdevries@mpic.de)

\section{Introduction}

Due to the large variety of sources, aerosol particles have strongly varying microphysical properties. As a consequence, aerosol optical properties (aerosol optical thickness (AOT), single scattering albedo $\left(\omega_{0}\right)$, and phase function), and their respective wavelength dependences can differ markedly for different aerosol types. This issue causes difficulties for the retrieval of aerosol parameters by passive satellite instruments. Another important complicating factor is the existence of an aerosol particle size distribution, rather than a single unique particle size: this causes a smooth, wavelength-dependent effect on remotely sensed optical spectra that is difficult to distinguish from changes in wavelength-dependent surface albedo. Also, aerosol parameters are usually not retrieved in the presence of clouds, meaning that many measurement points are discarded, and that results averaged over certain periods are biased towards cloudless scenarios.

Some thirteen years ago, a "new absorbing aerosol index" was introduced (Hsu et al., 1996) that was found to be very sensitive to UV-absorbing aerosols. This aerosol index is based on the measurement of the reflectance at two wavelengths in the UV coupled with radiative transfer modelling of the Rayleigh atmosphere. It was developed for TOMS, but in later years was adapted for use with GOME (Gleason et al., 1998; de Graaf et al., 2005a), SCIAMACHY (de Graaf et al., 2005b), and OMI (Torres et al., 2007). The Absorbing Aerosol Index (AAI) has proven to be very useful for studying UV-absorbing aerosols, in particular biomass burning aerosols (e.g. Hsu et al., 1996, 2003; Herman et al., 1997; Gleason et al., 1998; Fromm et al., 2005, 2006; de Graaf et al., 2006) and desert dust (e.g. Herman et al., 1997; Chiapello et al., 1999; Mahowald and Dufresne, 2004; Darmenova et al., 2005; de Graaf et al., 2006). This is despite the fact

Published by Copernicus Publications on behalf of the European Geosciences Union. 
that quantitative information on aerosol optical thickness or single- scattering albedo is hard to obtain due to the strong height dependence of AAI (Herman et al., 1997; Torres et al., 1998; Hsu et al., 1999; Mahowald and Dufresne, 2004). Three reasons that make AAI such a useful quantity are: (1) It is not very sensitive to surface type, which allows retrieval over land and water alike using the same algorithm. (2) The AAI can be retrieved in the presence of clouds, and is in fact even more susceptible to absorbing aerosols above strongly reflective surfaces (clouds, snow, ice) (Torres et al., 1998; Hsu et al., 2003; de Graaf et al., 2007). (3) The AAI contains information about aerosol layer height (Herman et al., 1997; Torres et al., 1998; Hsu et al., 1999; Mahowald and Dufresne, 2004; de Graaf et al., 2005a).

In this paper, we introduce the UV SCattering Index (SCI). It is defined as the negative part of the UV Aerosol Index (UVAI), just like the AAI is the positive part of the UVAI. Like the AAI, the SCI is an indicator for the presence of aerosols, in this case scattering aerosols (meaning aerosol particles with no or weak absorption in the UV range, $\left.\omega_{0}>0.9\right)$, and clouds. Although the fact that scattering aerosols cause negative UVAI values was acknowledged in the past (Herman et al., 1997; Torres et al., 1998; de Graaf et al., 2005a), to the authors' knowledge, no detailed investigations on the SCI have been performed so far.

We chose to use the SCIAMACHY instrument for this study because it has a lot of potential for characterizing aerosols in detail. The instrument covers a large wavelength range from the UV and the visible range to the near-IR. SCIAMACHY spectra are mainly used for trace gas analysis using the DOAS method (Platt and Stutz, 2008; Bovensmann et al., 1999; Wagner et al., 2008). SCIAMACHY offers the possibility to detect aerosol effects on radiance at many different wavelengths, in addition to providing information from trace gas absorption features that are also affected by the presence of aerosols (e.g. $\mathrm{O}_{2}$ or $\mathrm{O}_{4}$, see Koelemeijer et al., 2001; Wagner et al., 2004; van Diedenhoven et al., 2005). Such a large number of independent measurements may be of use for the accurate retrieval of aerosol optical properties in the near future. Another important advantage of the large wavelength range of SCIAMACHY is that aerosol properties can be studied at UV and visible wavelengths, where their signal is usually strongest, whereas clouds can be detected at visible to near-IR wavelengths, where the influence of aerosols is much weaker (e.g., de Graaf et al., 2007).

The paper is structured as follows: in the following three sections, we give a short explanation of the method (Sect. 2), and demonstrate the sensitivity of AAI and SCI to different aerosol (Sect. 3) and cloud (Sect. 4) parameters. In Sect. 5 we present our recent UV Aerosol Index results; the effect of a cloud filter on these results is illustrated in Sect. 6. Our data are subsequently compared to AERONET ground-based sun photometer measurements (Holben et al., 1998) in Sect. 7 , and the main conclusions of the paper are summarized in Sect. 8.

\section{Method}

The UVAI is essentially a measure of the change in the amount of Rayleigh scattered light observed at the top of atmosphere caused by the presence of scattering and absorbing particles (Herman et al., 1997; Torres et al., 1998). The UVAI is calculated using reflectances at two wavelengths in the UV range, $\lambda$ and $\lambda_{0}$. We selected $\lambda=335.5 \mathrm{~nm}$ and $\lambda_{0}=376.5 \mathrm{~nm}$, because at these wavelengths the reflectance is not strongly influenced by $\mathrm{O}_{3}$ and other trace gas absorption or Fraunhofer lines. The wavelengths also lie outside of the range of a broad spectral feature around $360 \mathrm{~nm}$ that is caused by an error in SCIAMACHY's radiometric calibration.

In analogy to UVAI from TOMS (Torres et al., 1998), we calculated the UVAI using the reflectance measured at $335 . \mathrm{nm}\left(R^{\text {meas }}\right)$, and that calculated using a radiative transfer model (RTM) at the same wavelength for an atmosphere devoid of aerosol $\left(R^{\text {Rayl }}\right)$. The UVAI is defined as (Torres et al., 1998):

$\mathrm{UVAI}=-100 \cdot\left({ }^{10} \log \left(\frac{R_{335.5}}{R_{376.5}}\right)^{\text {meas }}-{ }^{10} \log \left(\frac{R_{335.5}}{R_{376.5}}\right)^{\text {Rayl }}\right)$

The surface albedo for the calculation of $R^{\text {Rayl }}$ is derived from the measured reflectance at $376.5 \mathrm{~nm}$, so that $R^{\text {meas }}$ and $R^{\text {Rayl }}$ are equal at $376.5 \mathrm{~nm}$. It follows that:

$\mathrm{UVAI}=-100 \cdot{ }^{10} \log \left(\frac{R^{\text {meas }}}{R^{\text {Rayl }}}\right)_{335.5}$

For the calculation of UVAI, look-up tables (LUTs) were constructed that contain reflectances at $\lambda$ and $\lambda_{0}$ for a Rayleigh atmosphere with six surface albedo values between 0 and 1 . The LUTs were modelled using the RTM SCIATRAN 3.0, a successor to SCIATRAN 2.0 (Rozanov et al., 2002, 2005) (downloaded from: http://www.iup.physik. uni-bremen.de/sciatran/downloads/). Reflectances were calculated using the vector discrete ordinate method in a planeparallel atmosphere, taking polarisation into account. In earlier tests, it was found that including polarisation is critical to the correct calculation of UVAI (see de Graaf et al., 2005b).

In brief, the algorithm functions as follows. For each SCIAMACHY ground pixel reflectances at $\lambda$ and $\lambda_{0}$ are read out. Using the measured reflectance at $\lambda_{0}(376.5 \mathrm{~nm})$, the matching Rayleigh reflectance at $\lambda(335.5 \mathrm{~nm})$ is determined from a LUT based on the solar zenith angle (SZA), the viewing geometry (given by the line-of-sight zenith angle and the relative azimuth angle), and the average altitude of the ground pixel. The latter is determined by averaging of the GTOPO $0.1^{\circ} \times 0.1^{\circ}$ altitude world map (http://edc.usgs. gov/products/elevation/gtopo30/gtopo30.html). For regions with large altitude gradients systematic errors occur due to the under- or overestimation of the average altitude of the satellite pixel. Because we are at present not able to correct for these errors, we devised an altitude-gradient mask. For 
Table 1. Entries in the look-up-table used for the calculation of UV Aerosol Indices.

\begin{tabular}{lcccc}
\hline Variable & Minimum value & Maximum value & Step size & Number of entries \\
\hline Solar zenith angle & $15^{\circ}$ & $60^{\circ}$ & $5^{\circ}$ & 10 \\
Line-of-sight zenith angle & $0^{\circ}$ & $35^{\circ}$ & $5^{\circ}$ & 8 \\
Relative azimuth angle & $0^{\circ}$ & $180^{\circ}$ & $20^{\circ}$ & 10 \\
Surface altitude & $0 \mathrm{~km}$ & $6 \mathrm{~km}$ & $1 \mathrm{~km}$ & 7 \\
Surface albedo & 0 & 1 & variable & 6 \\
Wavelength & $335.5 \mathrm{~nm}$ & $376.5 \mathrm{~nm}$ & $41 \mathrm{~nm}$ & 2 \\
\hline
\end{tabular}

this purpose, the surface altitude of each satellite pixel (determined for the calculation of UVAI, as mentioned above) was mapped onto a grid with $0.5^{\circ} \times 0.5^{\circ}$ resolution and averaged for the studied time period (e.g. January-March, 2005 for the upper plot in Fig. 4). The resulting altitude map was compared with a GTOPO reference map with the same spatial resolution. Grid points with absolute altitude differences larger than $0.2 \mathrm{~km}$ were subsequently masked out on the average UVAI map. The application of the mask removes persistent artefacts in certain regions, particularly in the Himalayas and Andes, thereby increasing the reliability of the data. The altitude-gradient mask also causes a loss of data, therefore we are working on a method to calculate pixel average surface altitude more accurately so that in a future version of our UVAI algorithm, pixels with strong altitude gradients will be treated correctly.

The LUT entries and their respective ranges are given in Table 1. The LUT interpolation is done in two steps: in the first, a linear interpolation in six dimensions is performed to obtain six pairs of reflectances at 335.5 and $376.5 \mathrm{~nm}$, corresponding to the six surface albedo values. In the second step, this dependence is interpolated using a spline function to obtain the calculated reflectance at $335.5 \mathrm{~nm}$ matching the measured reflectance at $376.5 \mathrm{~nm}$.

The measured reflectance and the "looked up" Rayleigh reflectance at $335.5 \mathrm{~nm}$ are inserted into Eq. (2) to obtain the UVAI.

The positive part of UVAI is commonly defined as the Absorbing Aerosol Index (AAI); we define the negative part of UVAI as the new SCattering Index (SCI):

$\mathrm{AAI}=\mathrm{UVAI}$ for $\mathrm{UVAI} \geq 0$, undefined for UVAI $<0$

$\mathrm{SCI}=\mathrm{UVAI}$ for $\mathrm{UVAI} \leq 0$, undefined for $\mathrm{UVAI}>0$

The largest (more or less) random errors in the UVAI calculation are caused by inaccuracies in the calibration of SCIAMACHY radiances. The calibration errors in the absolute reflectances were corrected by multiplying the reflectances with a wavelength-dependent factor (as described in (Tilstra, 2008) and references therein). Due to the wavelength-dependent degradation of SCIAMACHY radiances the UVAI have been drifting to ever higher values since the end of 2004 (Tilstra et al., 2007). We have applied the so-called M-factors to correct the detected radiances for the effects of degradation (Bramstedt, 2007; see also http: //www.iup.uni-bremen.de/sciamachy/mfactors/). After the correction using M-factors, no apparent UVAI drift existed for the data presented here (from 2004 to 2006). Because the UVAI is determined by the ratio of two reflectances, as shown in Eq. (1), it is not particularly sensitive to the absolute reflectance value. It is difficult to determine the error from SCIAMACHY reflectance calibration issues, but the error of the relative reflectance $R_{335.5} / R_{376.5}$ is estimated to be on the order of $0.1 \%$ ( $\mathrm{S}$. Noël, personal communication, 2009), which would imply that the error is smaller than 0.1 UVAI units. Inaccuracies introduced by interpolation of the LUTs cause errors significantly smaller than 0.1 UVAI units, and the errors in the calculation of reflectances by SCIATRAN3.0 are negligibly small. Taking all these errors into account, we assume here that absolute UVAI values above $0.2-0.3$ are reliable.

Systematic errors can be introduced in areas with strongly varying surface altitude if the average surface altitude of the satellite pixel is not accurately determined. These errors can become quite large: on the order of 1 UVAI unit for an error in surface altitude of $0.6 \mathrm{~km}$. Surface albedo effects (e.g. over desert or ocean) can also cause large systematic errors, and will be discussed in more detail in the following section.

\section{Sensitivity of UVAI to aerosol and surface properties}

The subject of sensitivity of UVAI to various parameters has been addressed in several model studies. Herman and coworkers found a near-linear dependence of UVAI on aerosol optical thickness (AOT), and an equally strong dependence on aerosol layer altitude (Herman et al., 1997; Hsu et al., 1999; Mahowald and Dufresne, 2004). Of the other aerosol optical parameters, the single-scattering albedo $\left(\omega_{0}\right)$ has the largest influence on UVAI, especially if it is wavelengthdependent in the UV range (Torres et al., 1998; de Graaf et al., 2005a). We have modelled UVAI for many different combinations of aerosol parameters using the RTM SCIATRAN 3.0, and have found similar results as reported previously in (de Graaf et al., 2005a). To simplify the discussion 

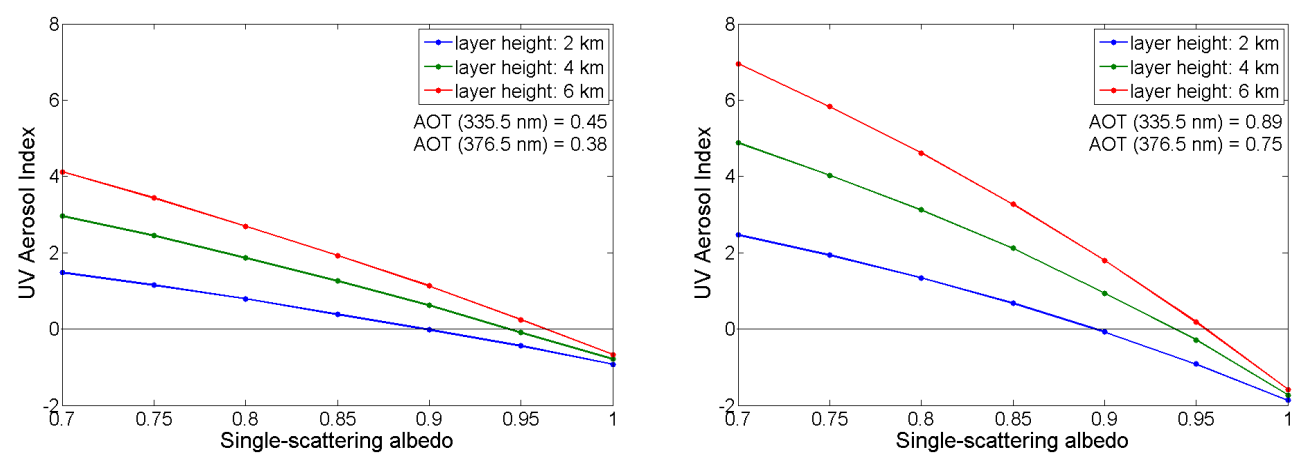

Fig. 1. Radiative transfer modelling (with SCIATRAN 3.0) of absorbing and scattering aerosols. UVAI were modelled for an aerosol layer as described in the text. Single-scattering albedo and layer height were varied as indicated in the figure. The layer had total aerosol optical thickness of 0.45 and 0.38 (left figure) or 0.89 and 0.75 (right figure) at 335.5 and $376.5 \mathrm{~nm}$, respectively, and a constant g-factor of 0.68 . Calculations were performed for nadir viewing geometry and a solar zenith angle of $20^{\circ}$.

of the results presented in the following sections, we summarize some of the results in Fig. 1. The dependence of UVAI on $\omega_{0}$ is shown for two values of AOT for aerosols with an Ångström coefficient of 1.5. The modelled aerosol extinction profile is triangle-shaped (a simplification of a Gaussian shape used in Torres et al., 1998) with a full width half maximum of $1 \mathrm{~km}$, and a maximum AOT at 2, 4, or $6 \mathrm{~km}$ altitude as shown in the figure legend.

Single-scattering albedo values were chosen to represent all types of aerosols from strongly UV-absorbing particles (biomass burning smoke particles, mineral dust; generally $\omega_{0}<0.9$ ) to purely scattering particles (sulphate or secondary organic aerosols, $\omega_{0}>0.9$ ).

In addition to their dependence on aerosol parameters, UVAI are sensitive to the scattering angle, i.e., solar zenith angle and viewing geometry (de Graaf et al., 2005a). Although UVAI are sensitive to the ozone total column, the effect is small (UVAI increase by 1 unit for a change from $100 \mathrm{DU}$ to $500 \mathrm{DU}$ for the $340 / 380 \mathrm{~nm}$ wavelength pair; de Graaf et al., 2005a), and is currently not taken into account in our algorithm.

As mentioned above, it was shown that neglect of polarisation in the calculation of the UVAI can lead to large errors, especially when the relative azimuth angle $<90^{\circ}$ (de Graaf et al., 2005b). Polarisation is of importance for radiative transfer modelling in the UV range because of the rather large number of polarising Rayleigh scattering events (Mishchenko et al., 1994) (on average approximately 2 at $\lambda=335.5 \mathrm{~nm}$ for clear sky, and this number increases with increasing surface reflectivity).

The UVAI are independent of surface type if the assumption is valid that surface albedo is equal at $\lambda$ and $\lambda_{0}$, the two wavelengths used for the calculation of UVAI. This is the case for the many surface types for which the albedo values vary by less than 0.005 (see, e.g., Kleipool et al., 2008), but there are at least three notable exceptions: the albedo of desert surfaces may be strongly wavelength dependent (e.g., the "bare" surface type in (Kleipool et al., 2008) has albedo values of 0.080 and 0.095 for 335.5 and $376.5 \mathrm{~nm}$, respectively). This may cause errors on the order of +1 UVAI unit, which should be borne in mind when UVAI over desert is observed. The two other exceptions occur on the ocean surface. The first is due to clear water absorption of solar radiation, and causes UVAI values up to about +1 (see also Sect. 5). The second is due to the presence of algae and coloured dissolved organic matter, mostly near coastlines, and causes negative UVAI values $(\mathrm{O}$. Torres, personal communication, 2009). Both of these contributions should be kept in mind when UVAI over ocean is studied.

\section{Sensitivity of UVAI to cloud properties}

The UVAI can be retrieved in presence of clouds, but it is strongly influenced by them. A cloud may affect the UVAI in three ways: first, by shielding the atmosphere below it from view, diminishing the effect of the aerosols below the cloud. Second, by enhancing the albedo for an aerosol layer above the cloud. This effect can strongly enhance UVAI for absorbing aerosols (Torres et al., 1998; Hsu et al., 2003; de Graaf et al., 2007). Third, the cloud itself may cause a significant UVAI signal, especially if it is a geometrically small or optically thin cloud. In the following, we will discuss the third effect in detail.

In Fig. 2 the results of a cloud sensitivity study are shown, in which clouds were modelled with either a fixed optical thickness of 50 and varying geometrical cloud fraction (CF) (thick clouds, left plot), or with varying optical thickness and fixed geometrical $\mathrm{CF}$ equal to 1 (thin clouds, right plot). The clouds are modelled as a Henyey-Greenstein-type aerosol with optical parameters obtained from Mie calculations assuming spherical cloud droplets $\left(\omega_{0}=1.00\right.$, asymmetry parameter $g=0.87$, negligible spectral dependence of the optical parameters in the UV and visible wavelength range, see, e.g., Wendisch et al., 2005). The UVAI are plotted against the 

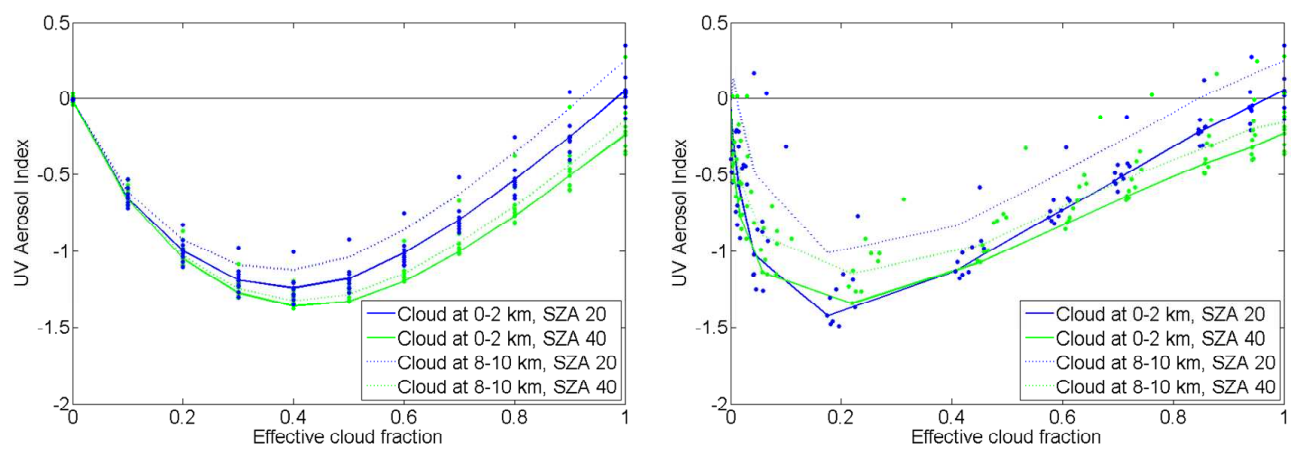

Fig. 2. Results from RTM calculations using SCIATRAN 3.0. Cloud parameters: single-scattering albedo 1.0, asymmetry parameter 0.87. Left: thick clouds with a total cloud optical thickness equal to 50 (cloud albedo equal to 0.8 ) with varying geometrical cloud fraction. Right: clouds with varying cloud optical thickness (between 0 and 50) and geometrical cloud fraction equal to 1 . Surface albedo was constant, and set to 0.05 . Calculations were performed for different SCIAMACHY viewing geometries (viewing angle $0-30^{\circ}$, relative azimuth angle $0-180^{\circ}$ ) and solar zenith angles of $20^{\circ}$ (in blue) and $40^{\circ}$ (in green). The clouds were located at $0-2 \mathrm{~km}$ altitude (solid lines and points), or at $8-10 \mathrm{~km}$ (dotted lines). The solid lines connect the points with nadir viewing geometry.
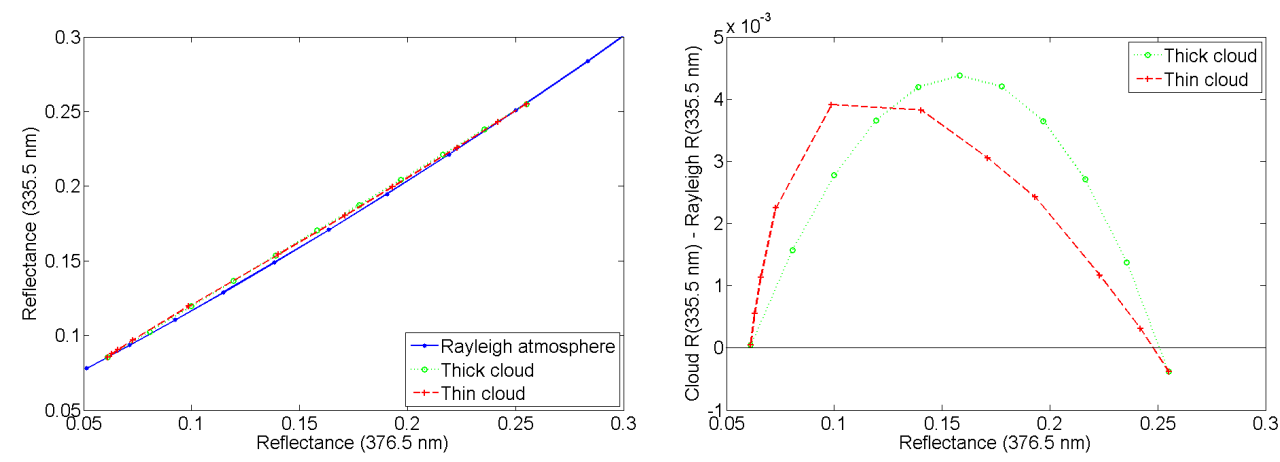

Fig. 3. Reflectances from RTM calculations using SCIATRAN 3.0. The same reflectances were used for the calculation of the results shown in Fig. 2 for the cloud at $0-2 \mathrm{~km}$ altitude with solar zenith angle $20^{\circ}$ and nadir viewing geometry. Left figure: absolute reflectances at two wavelengths in the UV range. Blue line and dots, Rayleigh atmosphere with surface albedo varying from 0.0 to 1.0 (from the LUT described in Sect. 2); green dotted line with circles, reflectances calculated for a thick cloud with CF between 0.0 and 1.0 as described in the text; red dashed line with pluses, reflectances calculated for a thin cloud with optical thickness between 0 and 50, as described in the text. Right figure: reflectances calculated for thick (green circles, dotted line) and thin clouds (red pluses, dashed line) as depicted in the left figure, but with the corresponding Rayleigh reflectance subtracted to emphasize the difference.

effective cloud fraction $\left(\mathrm{CF}_{\text {eff }}\right)$. In the FRESCO+ algorithm (Koelemeijer et al., 2001) $\mathrm{CF}_{\text {eff }}$ is defined as the linear combination of the 758-nm reflectance of a cloud-free pixel with that of a pixel covered by a homogeneous cloud with TOA albedo equal to 0.8. According to this definition, $\mathrm{CF}_{\text {eff }}$ is equal to the geometrical $\mathrm{CF}$ for thick (cloud optical thickness of 50), homogeneous clouds. We have adopted this method for our simulations, thus $\mathrm{CF}_{\text {eff }}$ is a linear function of the reflectance at $758 \mathrm{~nm}$, where a cloud-free scene has $\mathrm{CF}_{\text {eff }}=0$, and a scene with an optically thick, homogeneous cloud has $\mathrm{CF}_{\text {eff }}=1$.

In Fig. 2 it can be seen that UVAI depends strongly and non-linearly on $\mathrm{CF}_{\text {eff }}$, and is somewhat different for optically thin (geometrical $\mathrm{CF}=1$ ) and optically thick (optical thickness $=50$ ) clouds. The reason that clouds with $\mathrm{CF}_{\text {eff }}<1$ cause non-zero UVAI values is that such clouds affect the spectral contrast in the UV range in a different way than an increase in homogeneous surface albedo, as used in the calculation of UVAI, does. In the left plot in Fig. 3 simulated reflectances at $335.5 \mathrm{~nm}$ and at $376.5 \mathrm{~nm}\left(R_{335.5}\right.$ and $R_{376.5}$, respectively) are plotted against each other for three different cases: clear (Rayleigh) atmosphere with surface albedo varying between 0 and 1 ; thick clouds with $\mathrm{CF}_{\text {eff }}$ between 0 and 1 ; and thin clouds with $\mathrm{CF}_{\text {eff }}$ between 0 and 1. The reflectance of thick clouds was calculated using the independent-pixel approximation, therefore $R_{335.5}$ depends linearly on $R_{376.5}$. For thin clouds, RTM calculations show a similar, near-linear dependence of $R_{335.5}$ on $R_{376.5}$. In contrast, for a Rayleigh atmosphere with varying homogeneous surface albedo the dependence of $R_{335.5}$ on $R_{376.5}$ is 
distinctly non-linear. This can be seen more clearly in the right plot in Fig. 3, where the difference between cloud reflectances and corresponding Rayleigh reflectances at 335.5 $\mathrm{nm}$ is plotted against $R_{376.5}$. The non-linear behaviour of reflectance (w.r.t. surface albedo) is a result of multiple surface and Rayleigh scattering in the observed wavelength range. For a cloud-free atmosphere the average number of Rayleigh scatter events at the UVAI wavelengths initially decreases with increasing surface albedo, reaching a minimum for a surface albedo of 0.2 (at $335.5 \mathrm{~nm}$ ) or 0.4 (at $376.5 \mathrm{~nm}$ ), then increases approximately quadratic with increasing surface albedo (unpublished results). For clouds on the other hand, the number of Rayleigh scattering events increases linearly (near-linearly for thin clouds) with increasing TOA albedo. Consequently, the number of Rayleigh scattering events, and thus the spectral contrast between $335.5 \mathrm{~nm}$ and $376.5 \mathrm{~nm}$, is larger for clouds with $\mathrm{CF}_{\text {eff }}<1$ than for the corresponding Rayleigh case, leading to negative UVAI values according to Eq. (1). It is interesting, though not surprising, to note here that similar results are obtained for a pixel with heterogeneous surface albedo, consisting of a "dark" part (with small surface albedo, e.g., 0.05) and a "light" part (with large surface albedo, e.g., 0.80).

The most important results from the cloud-modelling study are that clouds with small $\mathrm{CF}_{\text {eff }}$ cause negative UVAI (non-zero $\mathrm{SCI}$ ), and that clouds with $\mathrm{CF}_{\text {eff }}$ between $5 \%$ and $50 \%$ cause the largest SCI. It is worth mentioning here that the non-linearity of the dependence of UVAI on CF makes it impossible to interpolate results obtained for clouds with $\mathrm{CF}_{\text {eff }}=1$ to partial and thin clouds: the conclusion that clouds have UVAI value close to 0 is clearly only valid for clouds with large $\mathrm{CF}_{\text {eff }}$.

The dependence of UVAI on $\mathrm{CF}_{\text {eff }}$ is shown for different viewing geometries by the blue and green points in Fig. 2 . These were calculated for viewing angles between $0^{\circ}$ and $30^{\circ}$, and for azimuth angles of $0^{\circ}, 90^{\circ}$, and $180^{\circ}$. The shape of the $\mathrm{CF}_{\text {eff }}$ dependence of UVAI is similar for all but the most extreme viewing angles for $\mathrm{SZA} \leq 40^{\circ}$, but becomes more strongly dependent on viewing geometry for $\mathrm{SZA}=60^{\circ}$ (not shown). The altitude of the clouds was also varied in this study, with the lowest cloud at $0-2 \mathrm{~km}$, and the highest at 12 $14 \mathrm{~km}$. In Fig. 2 it can be seen that the altitude of the cloud has only a minor influence on the UVAI, in agreement with Fig. 1 (for $\omega_{0}=1.0$ ). It is interesting to note, however, that high clouds with $\mathrm{CF}_{\text {eff }}$ close to 1 can cause small positive UVAI. The reason for this is that a high cloud shields a large fraction of the Rayleigh scattering molecules from sight of the satellite.

Simulations with $g$ values representative of ice clouds ( 0.75 to 0.90 , depending on ice crystal shape, see Wendisch et al., 2005) were also performed, and gave similar results as shown here for spherical particles $(g=0.87)$.

The modelling results presented here have obvious consequences for (average) AAI and SCI values, and indicate the importance of accounting for cloud effects when UVAI are to be used in a quantitative manner.

From Fig. 2 it follows that a cloud filter with a $\mathrm{CF}_{\text {eff }}$ threshold of $5 \%$ does not exclude contributions of small or thin clouds to the UVAI signal completely. Because the simple cloud fraction threshold is not an adequate filter for small and thin clouds, we are working on an improved cloud correction method for the UVAI that exploits the differences in wavelength dependence of cloud and aerosol optical parameters (most notably, optical thickness). For this, we will make use of SCIAMACHY's large wavelength range by using reflectances at large wavelengths to distinguish between the effects of clouds and aerosols. The cloud correction will be beneficial to both SCI and AAI, because thin clouds reduce the AAI in the same way as they enhance the SCI.

\section{Seasonal averages of UVAI}

In Fig. 4, we show results from our UVAI algorithm: seasonally averaged UVAI for the months January to March and for July to September, 2005. The colour scale was chosen to make absorbing aerosols appear in blue, scattering aerosols (those that absorb little or no UV radiation) and clouds in yellow and red. No cloud filtering was applied to obtain these figures (the effect of a cloud filter is demonstrated in the next section), but pixels in sun glint geometry (sun glint deviation angle $<18^{\circ}$, see Tilstra, 2008) were discarded. We removed pixels with SZA above $60^{\circ}$, because for higher SZA the UVAI become increasingly dependent on solar and viewing angles (see Fig. 1 in de Graaf et al., 2005a). We also applied a mask to remove pixels potentially affected by errors in the calculation of mean surface altitude, as explained in Sect. 2.

The principal sources of UV-absorbing aerosols are biomass burning and deserts. In the greater part of the socalled global dust belt (the world's largest deserts in Africa and Asia, located between $20^{\circ}-40^{\circ} \mathrm{N}$ ) the meteorological situation is most favourable for desert dust formation in June, July, and August, causing the largest AAI values to occur in those months. Biomass burning activity also depends on season: in December and January, many fires are found in sub-Saharan Africa, whereas from February to April, largescale agricultural burning takes place in Southeast Asia. On the Southern Hemisphere, most notably in the Amazon rainforest and in southern Africa, the biomass burning season peaks in August and September. The AAI results shown in Fig. 4 are very similar to previously shown results from GOME and SCIAMACHY (de Graaf et al., 2005a, b; see the TEMIS website at http://www.temis.nl/airpollution/absaai/), and from OMI (http://toms.gsfc.nasa.gov/aerosols/aerosols_ v8.html).

The SCI results have not been presented in this fashion before. In Fig. 4, there are some apparent hotspots concerning the SCI: in the Amazon (both plots), in southern 


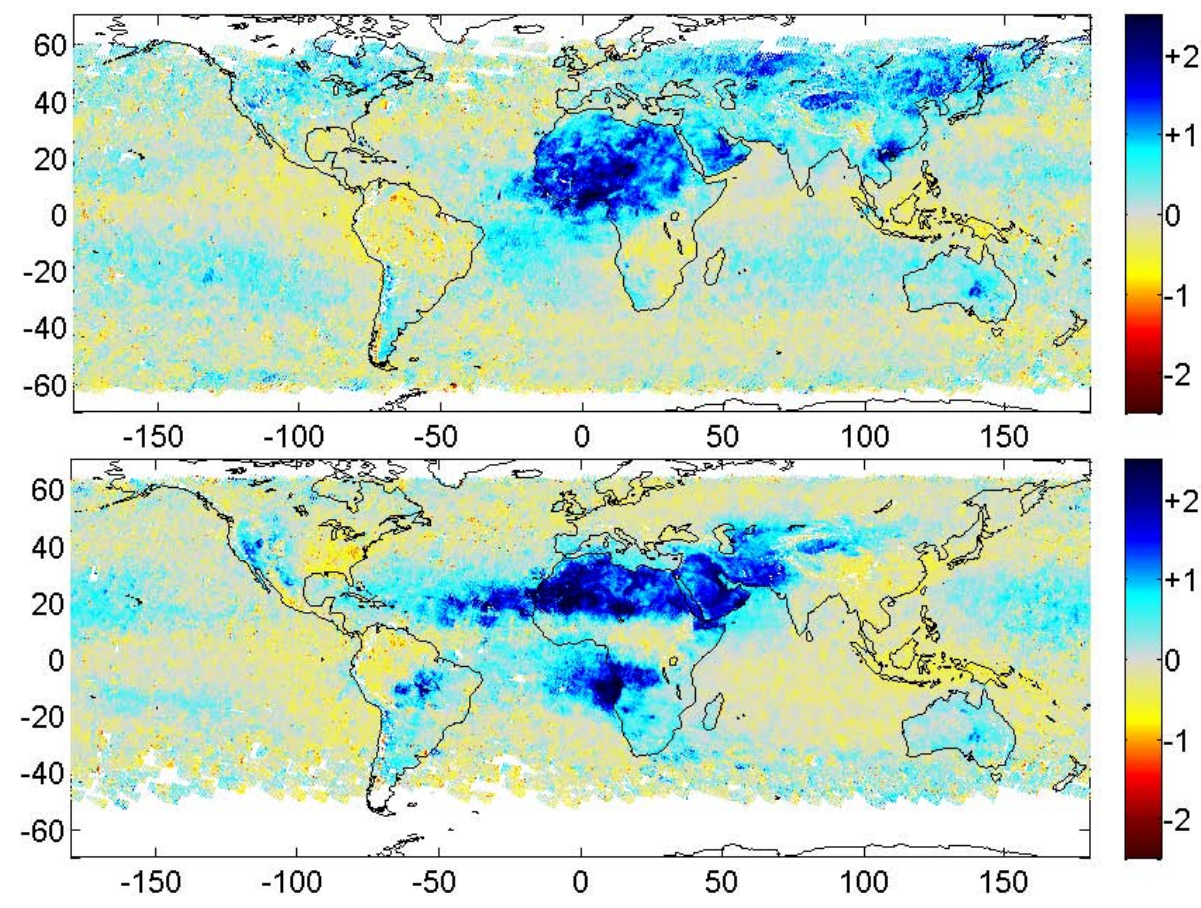

Fig. 4. Average UVAI for the months January, February, and March (upper figure) and July, August, and September (lower figure) 2005. Pixels with SZA $>60^{\circ}$ or in sun-glint geometry were removed. Pixels with strong altitude gradients are masked out. The blue colour indicates the presence of absorbing aerosols, whereas the yellow-red colour indicates scattering aerosols and clouds.

Africa (upper plot), and in central Africa, Southeast USA, and Southeast Asia (lower plot). Although clouds can make a significant contribution to the SCI (as discussed in detail below), we will provide evidence that these "hotspots" are most probably not - or not completely - caused by cloud cover.

\section{Cloud filter}

To eliminate cloud effects, we filtered the data shown in Fig. 4 by removing ground pixels containing cloud fractions higher than 5\% according to the HICRU algorithm (Grzegorski et al., 2006). The results are shown in Fig. 5. The threshold value of 5\% was chosen to remove most of the cloudy pixels without losing too many pixels containing aerosols misclassified as clouds. Geometrically small and optically thin (e.g. cirrus) clouds may escape the cloud filtering procedure, and are expected to contribute to the UVAI signal, as was discussed in Sect. 4.

When comparing Figs. 4 and 5, the effect of clouds on UVAI (mainly SCI) immediately becomes clear. Whereas in Fig. 4 the oceans are almost completely coloured yellow (SCI is around 1), in Fig. 5 a more grey background is seen, indicating a value much closer to 0 for most of the oceans (except for the regions with strong clear water absorption, where AAI is 0.5 or higher). The patterns of the absorbing aerosols remain the same after cloud-filtering of the data, although some pixels containing mineral dust over ocean have apparently been mistaken for clouds and have therefore been discarded. This may happen for scenes with AOT in the visible wavelength range on the order of 2 or higher. Also, in the lower figure most of the biomass burning plumes in the Amazon and especially in southern Africa have disappeared after cloud-filtering. The reason is that in these regions, absorbing aerosols often co-exist with clouds, in some cases forming an aerosol layer above low-lying clouds (see e.g., de Graaf et al., 2007; Chand et al., 2008). These pixels are discarded as a consequence of our cloud-filtering procedure.

The "SCI hotspots" mentioned in the previous section have remained after cloud-filtering. Their spatial and seasonal patterns (most notably in Southeast USA and Southeast Asia) appear to be in agreement with an enhanced amount of scattering aerosols in summertime. In addition, the average SCI values in these and other regions are much higher than would be expected from clouded scenes alone (as shown in Sects. 3 and 4). Nevertheless, the contribution of small and thin clouds that slipped through the cloud filter is significant in Fig. 5, e.g., over large parts of the oceans (although part of this signal might come from ocean colour effects and scattering aerosols). 


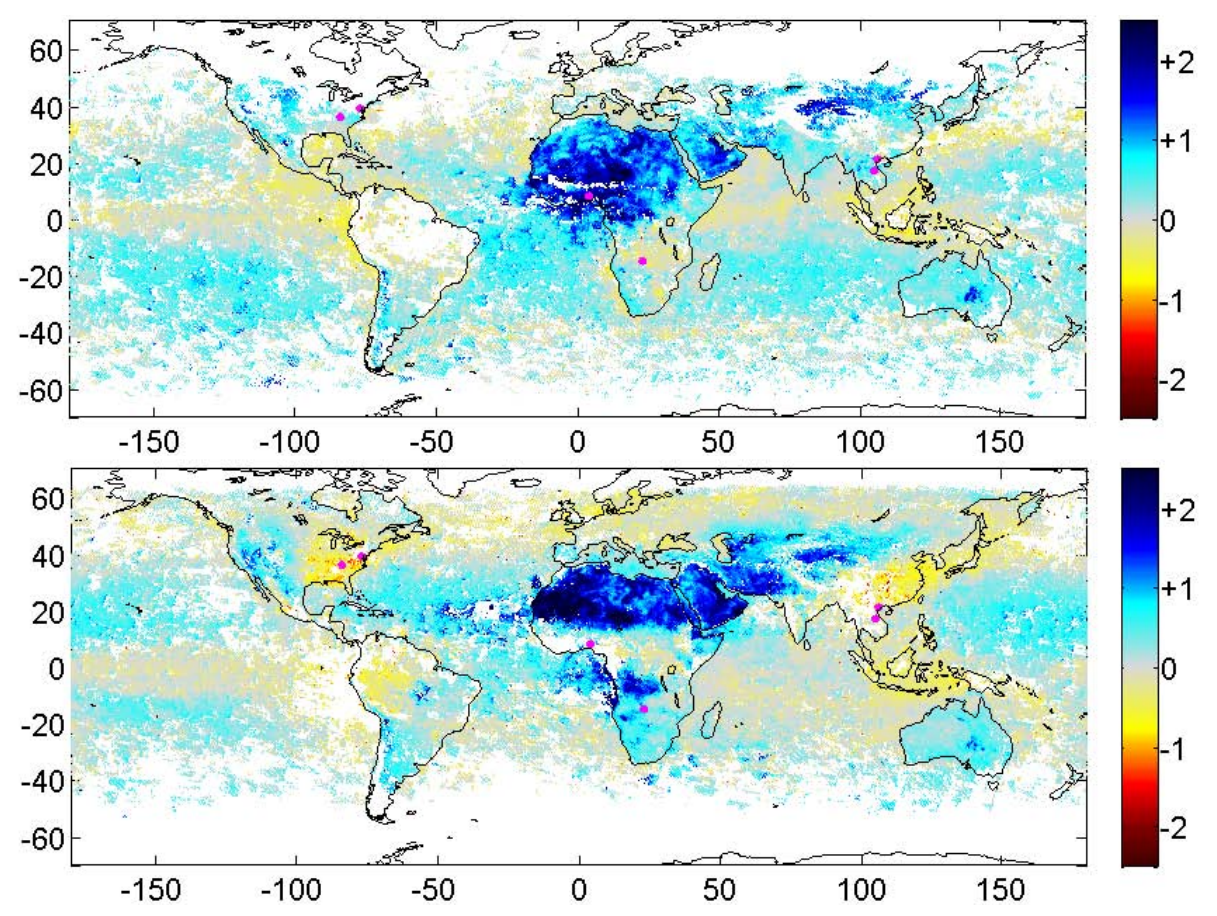

Fig. 5. Average UVAI for the months January, February, and March (upper figure) and July, August, and September (lower figure) 2005. Pixels with cloud fractions $>5 \%$ (determined by the HICRU algorithm (Grzegorski et al., 2006)) were discarded, as were pixels with SZA $>60^{\circ}$ and those in sun-glint geometry. Pixels with strong altitude gradients are masked out. The blue colour indicates the presence of absorbing aerosols, whereas the yellow-red colour indicates scattering aerosols and clouds. Magenta dots mark the locations of the AERONET sites studied in Sect. 7 (from West to East): Walker Branch (Tennessee), GSFC (Maryland), Ilorin (Nigeria), Mongu (Zambia), Mukdahan (Thailand), Bac Giang (Vietnam).

\section{Comparison of UVAI with AOT from AERONET}

Six ground-based sun photometer AERONET stations (Holben et al., 1998) were selected for a comparison with SCIAMACHY UVAI (see Fig. 5 for the locations of the AERONET stations). In Figs. 6-8 we show (from top to bottom) UVAI values from SCIAMACHY, and AOT (at $340 \mathrm{~nm}$ ) and $\omega_{0}($ at $440 \mathrm{~nm})$ from AERONET. For the UVAI averages, a region of $2^{\circ} \times 2^{\circ}$ around each AERONET station was selected, and UVAI data were averaged for the selected region either on a daily (blue dots) or a monthly (green dots and lines) basis for the years 2004-2006. The procedure was repeated for regions of $4^{\circ} \times 4^{\circ}$ around the AERONET stations with very similar results as presented here. Measurements where the HICRU cloud fraction exceeded $5 \%$ were discarded, as were measurements where SZA exceeded $60^{\circ}$. The UVAI data from the regions presented here were not affected by errors due to surface altitude gradients, except for data from the Walker Branch station, which is located north of a mountain range. To estimate the effect of the error due to inaccurate terrain height calculations, we determined average UVAI values for an area shifted northwards by $1^{\circ}$. Although errors of up to 0.5 UVAI units ( $0.3 \mathrm{~km}$ altitude error) for pixels located south of the AERONET station may be expected, the effects appear to be smoothed out by averaging and do not significantly affect the seasonal trend.

The data from AERONET are both daily (blue) and monthly (green) averaged cloud-cleared level 2.0 AOT data, measured at $340 \mathrm{~nm}$. AERONET measurements with SZA $>60^{\circ}$ were discarded, and only those data points are displayed that were measured within one hour of the satellite overpass time (10:30 a.m. local time at the equator). In the lower panels in Figs. 6-8, the AERONET level-1.5 singlescattering albedo values determined at $440 \mathrm{~nm}$ are shown. The value of $\omega_{0}$ depends on wavelength (Dubovik et al., 2002), with $\omega_{0}$ at $440 \mathrm{~nm}$ usually smaller than in the UV range. However, some aerosols are more absorbing in the UV range, for example in the case of mineral dust (Dubovik et al., 2002) or "brown" carbon aerosols (Kirchstetter et al., 2004; Barnard et al., 2008). For most of the examples shown in Figs. 6-8, $\omega_{0}$ at $440 \mathrm{~nm}$ appears to be a good indicator of absorbing ( $\omega_{0}$ roughly below 0.9$)$ and scattering $\left(\omega_{0}\right.$ roughly above 0.9) aerosols: high SCI values correspond to days with high AOT and high $\omega_{0}$, whereas high AAI values correspond to days with high AOT and low $\omega_{0}$.

Two of the AERONET stations are located in the southeast of the USA: Walker Branch (Tennessee) and GSFC (Maryland). At both stations high amounts of scattering aerosol 

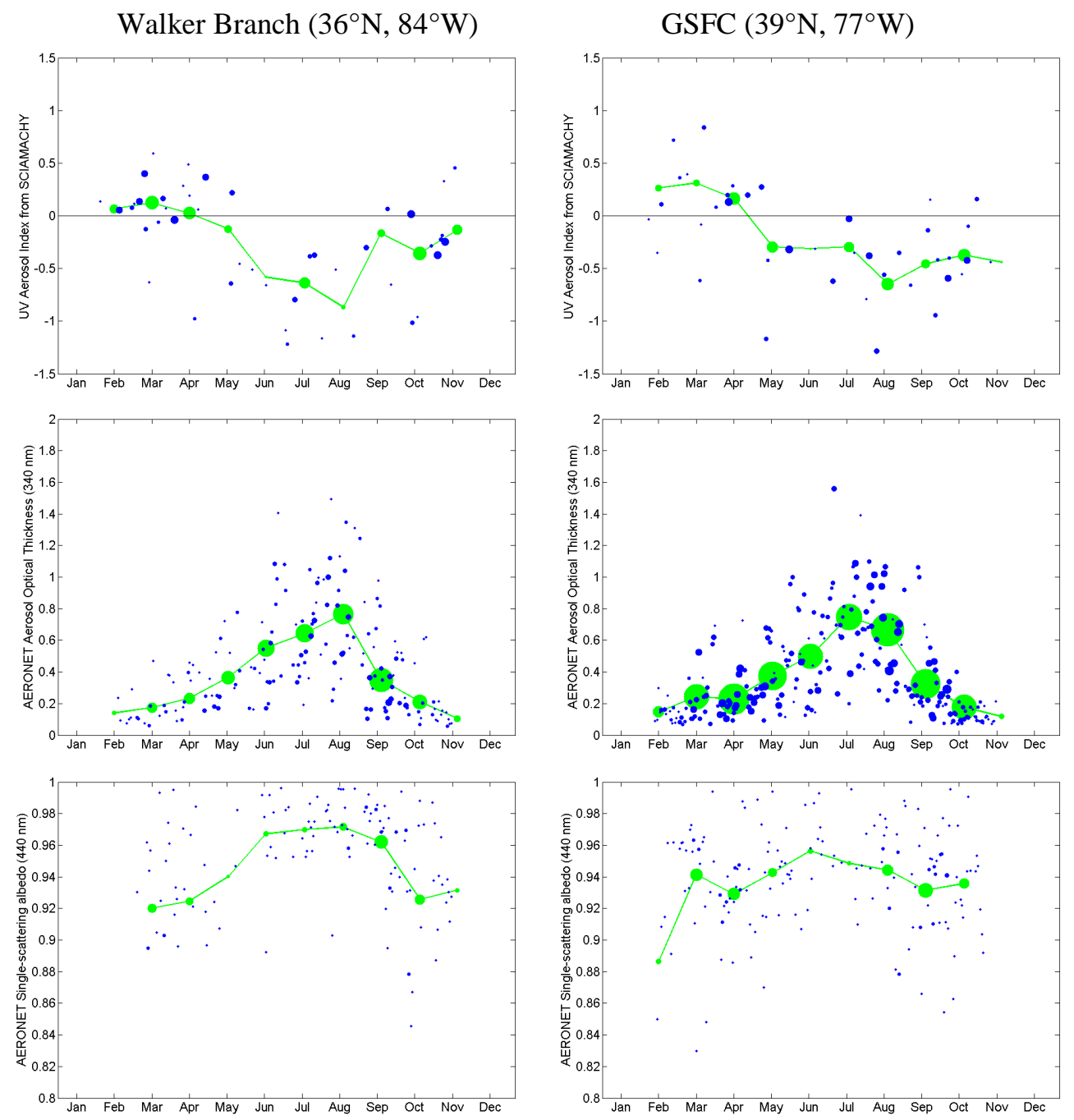

Fig. 6. Time series of aerosol parameters at two AERONET stations in the southeast of the USA, 2004-2006: left, Walker Branch (36 ${ }^{\circ}$, $\left.84^{\circ} \mathrm{W}\right)$; right, GSFC $\left(39^{\circ} \mathrm{N}, 77^{\circ} \mathrm{W}\right)$. Blue dots, daily averages; connected green dots, monthly averages. The size of the data points indicates the number of measurements included in the average value (minimum value: 1, maximum: 355 (monthly averaged AOT in August at GSFC)). Upper plots: daily and monthly averaged UVAI from SCIAMACHY. Pixels included in the averaging were in a $2^{\circ} \times 2^{\circ}$ box with the AERONET station in the centre. Pixels with SZA $>60^{\circ}$ or with HICRU CF $>5 \%$ were discarded. Middle plots: AOT at $340 \mathrm{~nm}$ (level 2.0) from AERONET. Measurements included in the average have SZA $<60^{\circ}$, and were measured between 09:30 and 11:30 a.m. (local time). Lower plots: single-scattering albedo at $440 \mathrm{~nm}$ (level 1.5) from AERONET. The same criteria as for AOT measurements apply. Details are given in the text.

particles are found in summer. This becomes clear from the upper plots in Fig. 6, where a summer minimum UVAI can be seen (more apparent at Walker Branch than at GSFC). In the plots with single-scattering albedo it can be seen that during summer, when AOT is high, the aerosols are highly reflective $\left(\omega_{0}\right.$ at $440 \mathrm{~nm}$ is between 0.94 and 1.0). This is in agreement with the hypothesis that the aerosols detected at GSFC and Walker Branch stations are mainly secondary organic aerosols formed by reactions of volatile organic compounds with atmospheric trace gases, such as $\mathrm{NO}_{\mathrm{x}}$ and $\mathrm{SO}_{\mathrm{x}}$ (Goldstein et al., 2009).
At the two stations in Africa, Mongu (Zambia) and Ilorin (Nigeria), the aerosol seasonal cycle is defined by the presence of biomass burning smoke during the dry season. For Mongu the dry season lasts from July to November, whereas in Ilorin it starts in November and ends in May/June. The seasonal trend can be recognized in the UVAI data shown in Fig. 7 (upper panel), where clear AAI maxima occur in September (Mongu) or January (Ilorin). The AAI maxima correspond to maximum AOT values (middle panel) and minima in the $\omega_{0}$ (lower panel) as measured by AERONET, confirming that large amounts of absorbing particles cause elevated AAI values. The exact value of UVAI is dependent 

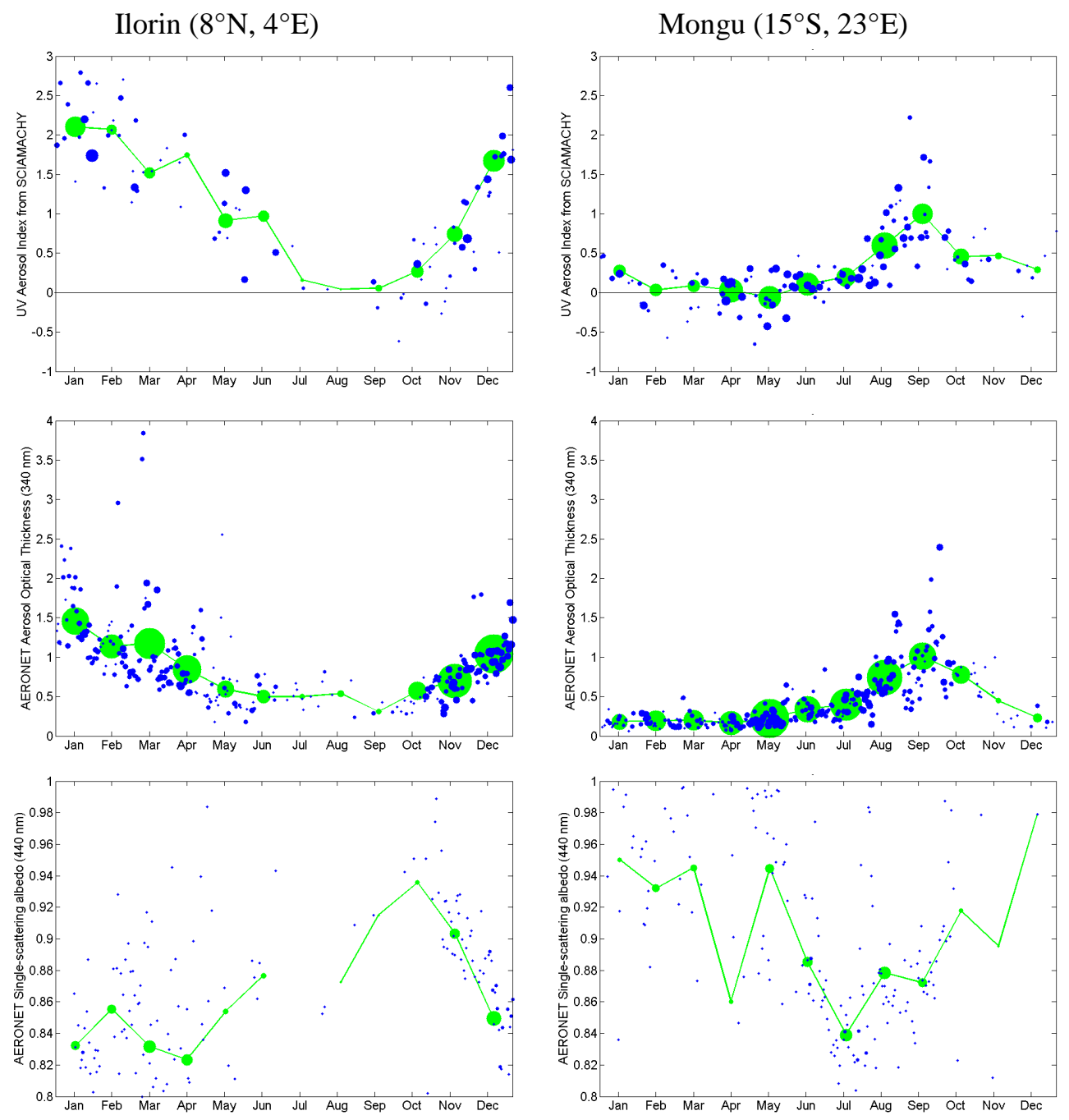

Fig. 7. Same as Fig. 6, but for two AERONET stations in Africa, 2004-2006: left, Ilorin $\left(8^{\circ} \mathrm{N}, 4^{\circ} \mathrm{E}\right)$; right, Mongu $\left(15^{\circ} \mathrm{S}, 23^{\circ} \mathrm{E}\right)$.

on aerosol layer height as well as AOT and $\omega_{0}$. This may be the reason that much higher AAI values are found at Ilorin than at Mongu, even though the AOT values measured at the two stations are roughly comparable. Good agreement between AAI and AOT was found in previous studies at various African AERONET sites (e.g., Hsu et al., 1999).

In Southeast Asia, the selected AERONET stations are located in Vietnam (Bac Giang) and Thailand (Mukdahan). Here, the situation is more complicated: in the first four months of the year, smoke from biomass burning activities (both local and transported) dominates the aerosol signal. High AOT values are found during this season, which peaks in March-April (Fig. 8). A second AOT peak can be discerned in the latter part of the year, with a maximum in August-October. These aerosols are characterized by high $\omega_{0}$ values (most clearly seen in the Mukdahan data). The seasonal pattern of UVAI correspondingly shows positive values during the biomass burning season (peaking in
March-April), and negative values in August-October (most clearly seen in Bac Giang, probably due to higher AOT).

The seasonal cycle is not very evident in the $\omega_{0}$ data, which may be caused by the fact that $\omega_{0}$ measured at $440 \mathrm{~nm}$ is not representative of $\omega_{0}$ in the UV range (see above). Alternatively, the apparent discrepancy may be due to the small number of $\omega_{0}$ measurements (factor of 6-7 smaller than the number of AOT measurements) at the two Southeast Asian AERONET sites, leading to bad statistics. It is, however, known from fire counts and other (satellite) data that a lot of biomass burning occurs in spring in Southeast Asia. In contrast, the high AOT values detected by AERONET in autumn cannot be attributed to either large-scale biomass burning or mineral dust particles, and therefore are, most likely, caused by scattering aerosols.

These examples demonstrate the importance of studying not only the positive UVAI values, but also the negative UVAI values: if only the AAI is studied, no aerosols 

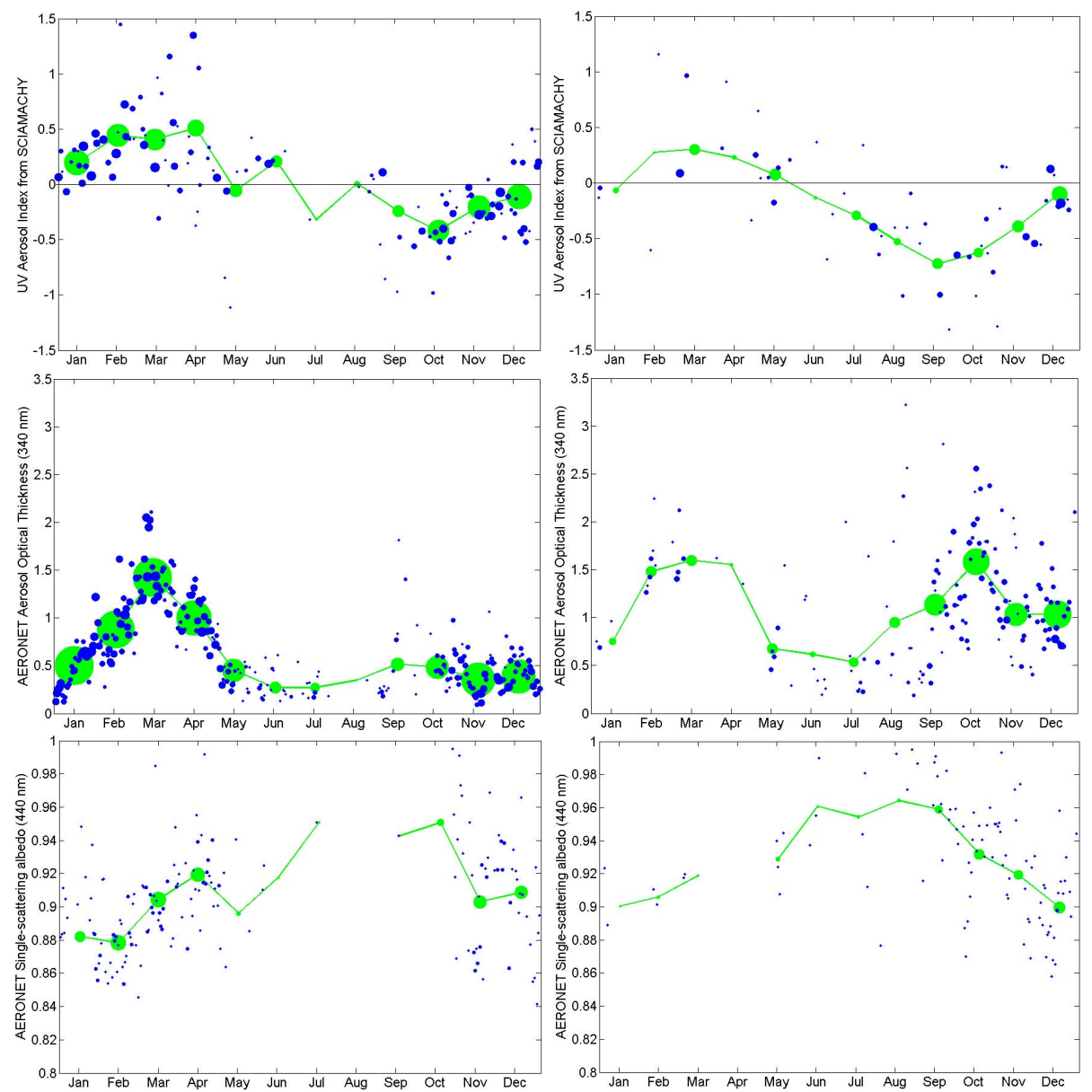

Fig. 8. Same as Fig. 6, but for two AERONET stations in Southeast Asia, 2004-2006: left, Mukdahan (17 $\left.{ }^{\circ} \mathrm{N}, 105^{\circ} \mathrm{E}\right)$; right, Bac Giang $\left(21^{\circ} \mathrm{N}, 106^{\circ} \mathrm{E}\right)$.

are detected at the two AERONET stations in the Southeast USA, and in Southeast Asia only the biomass burning aerosols would be observed.

\section{Conclusions}

In this paper we introduced the SCI as an indicator for the presence of scattering aerosols (that barely absorb UV radiation) and thin or partial clouds. The SCI is a counterpart to the established AAI, which has been used for over a decade as a semi-quantitative measure of aerosols that absorb UV radiation. Advantages of AAI include the insensitivity to most surface types and the possibility to calculate AAI in the presence of clouds. For the SCI, the same advantages apply, making it a useful tool for the monitoring of scattering aerosols.

For the correct interpretation of SCI and AAI, cloud effects have to be taken into account. We performed extensive modelling studies using the SCIATRAN3.0 radiative transfer model to obtain more insight into the sensitivity of UVAI to aerosol and cloud parameters. We found that clouds cause UVAI up to -1.5 for effective cloud fractions of approximately $30-50 \%$ (thick clouds), or $5-30 \%$ (thin clouds). The magnitude of cloud UVAI depends on solar and viewing angles, but the general shape of the dependence of UVAI on effective cloud fraction is very similar for all studied cases. A point worth mentioning is that high, thick clouds with large cloud fractions may cause (small) positive UVAI - therefore appearing as absorbing aerosols in certain cases.

If effects of clouds - i.e., shielding, albedo enhancement, but in particular the contribution of clouds to UVAI - are properly accounted for, the SCI can be used to study scattering aerosols. We note here, however, that desert and ocean regions need to be treated with caution: strongly wavelengthdependent surface albedo, as may occur in deserts or in ocean regions (either by clear-water absorption or due to the presence of coloured matter) can cause systematic errors of up to \pm 1 UVAI unit.

The global distribution of SCI (Figs. 4 and 5), its seasonal cycle, and the high seasonally averaged SCI values in 
certain regions (in particular, Southeast USA and Southeast Asia) are indications that scattering aerosols (and not only clouds) are being detected. The good overall agreement of monthly averaged SCI and AOT (Fig. 6) at the GSFC and Walker Branch AERONET stations is a good argument that $\mathrm{SCI}$ is, indeed, an indicator of scattering aerosols. The UVAI also follows the complex seasonal behaviour of aerosols at the Bac Giang and Mukdahan AERONET stations, with enhanced amounts of absorbing aerosols causing positive UVAI in spring, and enhanced amounts of scattering aerosols causing negative UVAI during summer.

It is important to stress here that both AAI and SCI are quantities that depend in complex ways on aerosol absorption and aerosol layer altitude, as well as on aerosol optical thickness. In particular, negative UVAI values can be caused by (a low-altitude layer of) absorbing aerosols, just as positive UVAI values can be associated with (a high-altitude layer of) scattering aerosols (see Fig. 1 and Herman et al., 1997; Torres et al., 1998; de Graaf et al., 2005a).This means that the UVAI are not sufficient for the retrieval of aerosol (optical) properties directly. However, if two of these properties (e.g., aerosol optical thickness and layer height) are known, the UVAI can be used to determine the single-scattering albedo - a parameter of significance for the quantification of aerosol radiative effects. Only if the full extent of UVAI - AAI as well as SCI - is regarded, a complete picture of aerosol absorption can be obtained.

In the future, we intend to combine aerosol absorptive properties inferred from UVAI with auxiliary information, e.g. AOT and/or aerosol layer altitude from SCIAMACHY (reflectances in the visible, absorptions, or Raman scattering effects) or from other satellite instruments in order to calculate aerosol radiative effects.

We plan to also use UVAI from data from other satellite instruments such as GOME-2 and OMI. These instruments achieve global coverage nearly daily, and consequently provide us with better statistics. We will also use the aerosol information from UVAI to improve trace gas retrievals, in particular by improving the calculation of air-mass factors that are used for the derivation of the vertical column density from the slant column density.

Acknowledgements. U. Platt, U. Pöschl, M. O. Andreae, A. Kokhanovsky, P. Stammes, and O. Torres are thanked for helpful discussions. IUP Bremen, A. Rozanov and V. Rozanov are kindly thanked for providing a pre-release version of SCIATRAN 3.0 (from http://www.iup.physik.uni-bremen.de/sciatran/downloads/), and for their excellent technical support. We would like to thank the ESA (European Space Agency) and the DLR (Deutsches Zentrum für Luft- und Raumfahrt) for providing us with the L1b SCIAMACHY data files. The US Geological Survey is acknowledged for making their topological data accessible (at http://edc.usgs.gov/products/elevation/gtopo30/gtopo30.html).

We also thank the AERONET principal investigators B. Holben, R. Pinker, N. X. Anh, and their staff for establishing and maintaining the GSFC, Walker Branch, Mongu, Mukdahan, Ilorin, and Bac Giang sites. AERONET data were downloaded from: http://aeronet.gsfc.nasa.gov/.

M. P. d. V. acknowledges the Max Planck Society for a research grant.

The service charges for this open access publication have been covered by the Max Planck Society.

Edited by: A. Richter

\section{References}

Barnard, R., Volkamer, R., Kassianov, E. I.: Estimation of the mass absorption cross section of the organic carbon component of aerosols in the Mexico City Metropolitan Area (MCMA), Atmos. Chem. Phys., 8, 6665-6679, 2008, http://www.atmos-chem-phys.net/8/6665/2008/.

Bovensmann, H., Burrows, J. P., Buchwitz, M., Frerick, J., Noël, S., Rozanov, V. V., Chance, K. V., and Goede, A. P. H.: SCIAMACHY: Mission objectives and measurements modes, J. Atmos. Sci., 56, 127-150, 1999.

Bramstedt, K.: Calculation of SCIAMACHY M-Factors, IUP Bremen, IFE-SCIA-TN-2007-01-CalcMFactor, 2007.

Chand, D., Anderson, T. L., Wood, R., Charlson, R. J., Hu, Y., Liu, Z., and Vaughan, M.: Quantifying above-cloud aerosol using spaceborne lidar for improved understanding of cloudysky direct climate forcing, J. Geophys. Res., 113, D13206, doi:10.1029/2007JD009433, 2008.

Chiapello, I., Prospero, J. M., Herman, J. R., and Hsu, N. C.: Detection of mineral dust over the North Atlantic Ocean and Africa with the Nimbus 7 TOMS, J. Geophys. Res., 104(D8), 92779291, 1999.

Darmenova, K., Sokolik, I. N., and Darmenov, A.: Characterization of east Asian dust outbreaks in the spring of 2001 using ground-based and satellite data, J. Geophys. Res., 110, D02204, doi:10.1029/2004JD004842, 2005.

van Diedenhoven, B., Hasekamp, O. P., and Aben, I.: Surface pressure retrieval from SCIAMACHY measurements in the $\mathrm{O}_{2}$ A Band: validation of the measurements and sensitivity on aerosols, Atmos. Chem. Phys., 5, 2109-2120, 2005 , http://www.atmos-chem-phys.net/5/2109/2005/.

Dubovik, O., Holben, B., Eck, T. F., Smirnov, A., Kaufman, Y. J., King, M. D., Tanré, D., and Slutsker, I.: Variability of absorption and optical properties of key aerosol types observed in worldwide locations, J. Atmos. Sci., 59, 590-608, 2002.

Fromm, M., Bevilacqua, R., Servanckx, R., Rosen, J., Thayer, J. P., Herman, J., and Larko, D.: Pyro-cumulonimbus injection of smoke to the stratosphere: Observations and impact of a super blowup in northwestern Canada on 3-4 August 1998: J. Geophys. Res., 110, D08205, doi:10.1029/2004JD005350, 2005.

Fromm, M., Tupper, A., Rosenfeld, D., Servanckx, R., and McRae, R.: Violent pyro-convective storm devastates Australia's capital and pollutes the stratosphere, Geophys. Res. Lett., 33, L05815, doi:10.1029/2005GL025161, 2006.

Gleason, J. F., Hsu, N. C., and Torres, O.: Biomass burning smoke measured using backscattered ultraviolet radiation: SCAR-B and Brazilian smoke interannual variability, J. Geophys. Res., 103(D24), 31969-31978, 1998.

Goldstein, A. H., Koven, C. D., Heald, C. L., and Fung, I.: Biogenic Carbon and Anthropogenic Pollutants Combine to Form a 
Cooling Haze over the Southeastern US, Proc. Natl. Acad. Sci., 106, 8835-8840, doi:10.1073/PNAS.0904128106, 2009.

de Graaf, M., Stammes, P., Torres, O., and Koelemeijer, R. B. A.: Absorbing Aerosol Index - Sensitivity analysis, application to GOME and comparison with TOMS, J. Geophys. Res., 110, D01202, doi:10.1029/2004JD005178, 2005a.

de Graaf, M. and Stammes, P.: SCIAMACHY Absorbing Aerosol Index -Calibration issues and global results from 2002-2004, Atmos. Chem. Phys., 5, 2385-2394, 2005b, http://www.atmos-chem-phys.net/5/2385/2005/.

de Graaf, M., Stammes, P., and Aben, E. A. A.: Analysis of reflectance spectra of UV-absorbing aerosol scenes measured by SCIAMACHY, J. Geophys. Res., 112, D02206, doi:10.1029/2006JD007249, 2007.

Grzegorski, M., Wenig, M., Platt, U., Stammes, P., Fournier, N., and Wagner, T.: The Heidelberg iterative cloud retrieval utilities (HICRU) and its application to GOME data, Atmos. Chem. Phys., 6, 4461-4476, 2006, http://www.atmos-chem-phys.net/6/4461/2006/.

Herman, J. R., Bhartia, P. K., Torres, O., Hsu, C., Seftor, C., and Celarier, E.: Global distribution of UV-absorbing aerosols from Nimbus 7/TOMS data, J. Geophys. Res., 102(D14), 1691116922, 1997.

Holben, B. N., Eck, T. F., Slutsker, I., Tanré, D., Buis, J. P., Setzer, A., Vermote, E., Raegan, J. A., Kaufman, Y. J., Nakajima, T., Lavenu, F., Jankowiak, I., and Smirnov, A.: AERONET - A federated instrument network and data archive for aerosol characterization, Remote Sens. Environ., 66, 1-16, 1998.

Hsu, N. C., Herman, J. R., Bhartia, P. K., Seftor, C. J., Torres, O., Thompson, A. M., Gleason, J. F., Eck, T. F., and Holben, B. N.: Detection of biomass burning smoke from TOMS measurements, Geophys. Res. Lett., 23(7), 745-748, 1996.

Hsu, N., Herman, J., Torres, O., Holben, B., Tanre, D., Eck, T., Smirnov, A., Chatenet, B., and Lavenu, F.: Comparisons of the TOMS aerosol index with Sun-photometer aerosol optical thickness: Results and applications, J. Geophys. Res., 104(D6), 62696279, 1999.

Hsu, N. C., Herman, J. R., and Tsay, S.-C.: Radiative impacts from biomass burning in the presence of clouds during boreal spring in southeast Asia, Geophys. Res. Lett., 30, 1224, doi:10.1029/2002GL016485, 2003.

Kirchstetter, T. W., Novakov, T., and Hobbs, P. V.: Evidence that the spectral dependence of light absorption by aerosols is affected by organic carbon, J. Geophys. Res., 109, D21208, doi:10.1029/2004JD004999, 2004.

Koelemeijer, R. B. A., Stammes, P., Hovenier, J. W., de Haan, J. F.: A fast method for retrieval of cloud parameters using oxygen A band measurements from the Global Ozone Monitoring Experiment, J. Geophys. Res., 106, 3475-3490, 2001.

Mahowald, N. M. and Dufresne, J.-L.: Sensitivity of TOMS aerosol index to boundary layer height: Implications for detection of mineral aerosol sources, Geophys. Res. Lett., 31, L03103, doi:10.1029/2003GL018865, 2004.
Mishchenko, M. I., Lacis, A. A., and Travis, L. D.: Errors induced by the neglect of polarisation in radiance calculations for Rayleigh-scattering atmospheres, J. Quant. Spectrosc. Radiat. T., 51, 3, 491-510, 1994.

Platt, U. and Stutz, J.: Differential Optical Absorption Spectroscopy: Principles and Applications, Physics of Earth and Space Environment Series edited by: Guzzi, R., Lanzerotti, L., and Platt, U., Springer, 2008.

Rozanov, V. V., Buchwitz, M., Eichmann, K.-U., de Beek, R., and Burrows, J. P.: SCIATRAN - A new radiative transfer model for geophysical applications in the $240-2400 \mathrm{~nm}$ spectral region: the pseudo-spherical version, Adv. Space Res., 29(11), 1831-1835, 2002.

Rozanov, A., Rozanov, V., Buchwitz, M., Kokhanovsky, A., and Burrows, J. P.: SCIATRAN 2.0 - A new radiative transfer model for geophysical applications in the $175-2400 \mathrm{~nm}$ spectral region, Adv. Space Res. 36, 1015-1019, 2005.

Tilstra, L. G., de Graaf, M., Noël, S., Aben, I., and Stammes, P.: SCIAMACHY's Absorbing Aerosol Index and the consequences of instrument degradation, Proc. ACVE-3, 2007.

Tilstra, L. G.: SCIAMACHY Absorbing Aerosol Index Algorithm Theoretical Basis Document, SRON-EOS-RP-08-023, 2008.

Torres, O., P. K. Bhartia, J. R. Herman, Z. Ahmad, J. Gleason: Derivation of aerosol properties from satellite measurements of backscattered ultraviolet radiation: Theoretical basis, J. Geophys. Res., 103(D14), 17099-17110, 1998.

Torres O., Tanskanen, A., Veihelmann, B., Ahn, C., Braak, R., Bhartia, P. K., Veefkind, P., and Levelt, P.: Aerosols and surface UV products from Ozone Monitoring Instrument observations: An overview, J. Geophys. Res., 112, D24S47, doi:10.1029/2007JD008809, 2007.

Wagner, T., Dix, B., Friedeburg, C. v., Friess, U., Sanghavi, S., Sinreich, R., and Platt, U.: MAX-DOAS O 4 measurements - A new technique to derive information on atmospheric aerosols, J. Geophys. Res., 109, D22205, doi:10.1029/2004JD004904, 2004.

Wagner, T., Beirle, S., Deutschmann, T., Eigemeier, E., Frankenberg, C., Grzegorski, M., Liu, C., Marbach, T., Platt, U., and Penning de Vries, M.: Monitoring of atmospheric trace gases, clouds, aerosols and surface properties from UV/vis/NIR satellite instruments, J. Opt. A: Pure Appl. Opt., 10, 104019, doi:10.1088/1464-4258/10/10/104019, 2008.

Wendisch, M., Pilewskie, P., Pommier, J., Howard, S., Yang, P., Heymsfield, A. J., Schmitt, C. G., Baumgardner, D., and Mayer, B.: Impact of cirrus crystal shape on solar spectral irradiance: A case study for subtropical cirrus, J. Geophys. Res., 110, D03202, doi:10.1029/2004JD005294, 2005. 